\title{
Mais Um Final de Ano, Mais Um Ano de Sucesso!
}

O TEMPO PASSA MAIS RÁPIDO à medida que você se torna cada vez mais, digamos, maduro. Esta é uma constatação que somente agora consigo vivenciar e apreciar na íntegra, mas que, ouvindo de minha mãe em anos passados, me soava apenas como um queixume de gente mais velha.

Nunca soube avaliar corretamente o que Einstein quis dizer com $\mathrm{E}=\mathrm{mc}^{2}$, mas depreendo que a energia (especialmente a nossa) tem algo a ver com o tempo, cuja velocidade é, também, indireta e geometricamente proporcional à exiquidade de prazos que você tem para completar seus afazeres. Na sábia voz do povo: "O tempo vôa e não sobra tempo prá nada!”

Não digo isso à toa, nem por falta de assunto. É que já estamos nos últimos dias do ano, no encerramento do começo do novo século, que apenas há pouco eu ainda saudava em editorial. Parece-me até que foi no anterior.

Mas no anterior (edição especial Comemorativa do Cinqüentenário dos ABE\&M), na verdade, dizia que não completei o texto e o pensamento sobre aspectos históricos e bibliográficos dos "Arquivos" porque não somente não dispunha de espaço suficiente, como pretendia, em seguida, detalhar com parâmetros bibliométricos, orçamentários e outros - pitorescos -, da minha gestão frente aos "Arquivos", à propósito de prestação de contas aos colegas e à nossa sociedade científica. Duas razões me fizeram optar por postergar este relato. A primeira foi porque o tempo voou e eu não me dei conta de que já estávamos praticamente na última edição do ano, quando, tradicional e respeitosamente, apenas agradeço aos inúmeros colaboradores, e a segunda, talvez ainda mais importante, porque esta "prestação de contas" merece um espaço e uma dedicação maiores. Por isto, programei já para o início de 2002 uma série de 3 editoriais, nos quais deverei expor pormenorizadamente aspectos evolutivos da revista em contraste e em comparação com períodos editoriais anteriores e contabilizar valores financeiros do período, acrescentando alguns dados estatísticos novos e curiosos.

Mas hoje é o final de mais um ano e, graças a Deus, bem sucedido. Aos leitores pode parecer longo e enfadonho o que passo a fazer. Acredito, entretanto, pela vivência da posição, que isto é sempre pouco e muito aquém do que é realmente devido. Não tendo a pretensão de que esta lista seja completa e, por precaução, já peço desculpas aos que não foram lembrados.

No final de 2000 antevi que o início do século seria auspicioso para a revista. Pois bem, neste ano de 2001 tivemos a satisfação de produzir 12 edições dos Arquivos, propiciando a média de uma edição por mes!. Revista mensal? Ainda é cedo, mas graças aos suplementos estamos chegando lá. Mais que isto, a quantidade de material científico (vocês verão nos prometidos editoriais futuros) não foi sacrificada; até aumentou. A periodicidade da revista está sendo rigorosamente respeitada e, quase invariavelmente, as edições são distribuídas no mesmo mês de referência. Adicionalmente, estamos visíveis em bases de dados virtuais respeitáveis, dentre as quais o Projeto SciELO.

Por isso e muito mais, quero agradecer a todos que de alguma maneira mostraram-se participativos. Inicialmente agradeço aos colaboradores que enviaram suas contribuições ao longo do ano (mais de 80 submissões), muitos deles tendo seus trabalhos já publicados no período e outros ainda aguardando a oportunidade. Lembro que durante o ano de 2001 todos os primeiros autores de artigos científicos originais efetivamente publicados nos ABE\&M estão concorrendo aos Prêmios ABE\&M: Prof. Thales Martins (melhor trabalho na área básica) e Prof. Waldemar Berardinelli (melhor trabalho na área clínica), conforme previamente informado e a serem anunciados no começo do próximo ano e entregues, provavelmente, em Março de 2002.

\section{Claudio E. Kater}

Editor-chefe, ABE\&M 
Agradeço a Luiz de Lacerda Filho e Margaret Boguszewski e a Ricardo Meirelles que, como editores convidados, coordenaram com maestria as maravilhosas Edições Especiais de 2001 sobre "Endocrinologia Pediátrica" e "Endocrinologia Feminina", respectivamente. Apenas como aperitivo, no próximo ano os leitores deverão estar saboreando "O Laboratório em Endocrinologia" e "Biologia Molecular em Endocrinologia", tendo como editores convidados respectivamente José Gilberto Vieira e Ana Claudia Latrônico.

Pela atenção e compreensão e, mais que isto, pela presteza (e, claro, pela qualidade) sou muitíssimo grato aos editorialistas das edições deste ano (em ordem cronológica): Luiz de Lacerda Filho, Margaret Boguszewski, Turíbio Leite de Barros Neto, Rui M.B. Maciel, Ricardo M.R. Meirelles, Adriana Costa e Forti, Marcio C. Mancini, Amélio F. Godoy Matos, Cristina Dissat e João Hamilton Romaldini.

Agradeço, também, aos coordenadores dos suplementos dos ABE\&M publicados em 2001, trazendo temas-livres e material científico apresentado nos seguintes simpósios e congressos da especialidade: IX Congress of LATS - The Latin American Thyroid Society (vol. 45. no. 2, supl.1, abril 2001), IV COPEM - Congresso Paulista de Endocrinologia e Metabologia (vol. 45. no. 2, supl.2, maio 2001), 90. SISO - Congresso Brasileiro de Obesidade (vol. 45. no. 4, supl.1, agosto 2001), IV COBRAPEM - Congresso Brasileiro Pediátrico de Endocrinologia e Metabologia (vol. 45. no. 4, supl.2, setembro 2001) e XIII Congresso Brasileiro de Diabetes (vol. 45. no. 5, supl.1, outubro 2001). Um acontecimento marcante foi a edição histórica comemorativa do Cinqüentenário dos ABE\&M (vol. 45. no. 5, supl.2, novembro 2001), recém distribuída e que traz republicações de artigos históricos e memoráveis de anos passados e inúmeras colaborações atuais, com ênfase especial nas contribuições de Ubiratan Fabres Machado e Carlos Alberto Longui, presidentes respectivamente dos Departamentos de Endocrinologia Básica e Endocrinologia Pediátrica da SBEM. Ambos fizeram atualizações após 50 anos dos dois primeiros artigos publicados na revista em 1951, respectivamente por Thales Martins e Waldemar Berardinelli, fundadores e primeiros editores dos "Arquivos".

Sou grato, mais do que justamente, aos meus colaboradores mais próximos - co-responsáveis pela manutenção da pontualidade e do padrão de qualidade da revista -, os membros das Comissões Editoriais, Nacional e Internacional, e o profícuo Conselho de Revisores. Neste ano em particular quero agradecer às seguintes pessoas (em ordem alfabética de primeiro nome): Adriana Costa e Forti, Amélio F. Godoy Matos, Ana Claudia Ramalho, Ana Luiza Maia, Ana Maria J. Lengyel, Ângela J. Reichelt, Antonio Carlos Bonaccorsi, Antonio Carlos Lerario, Antônio Roberto Chacra, Ayrton C. Moreira, Balduíno Tschiedel, Bernardo L. Wajchenberg, Bernardo Liberman, Carlos Alberto Longui, César L. Boguszewski, Dolores P. Pardini, Durval Damiani, Eduardo Pimentel Dias, Eduardo Tomimori, Geraldo Medeiros-Neto, Gil Guerra Jr., Hans Graf, Ieda T.N. Verreschi, Ivani N. Silva, Jader B. Ferreira (em nome dos colegas do SOCOR), João Roberto de Sá, Jorge Luiz Gross, José Egídio P. de Oliveira, José Osmar Medina Pestana, Laércio J. Franco, Laura S. Ward, Léa M.Z. Maciel, Leila M.B. Araújo,
Leonardo M. Diniz, Lucio Vilar, Luiz Cesar Póvoa, Luiz de Lacerda Filho, Luiz Roberto Ramos, Marcello D. Bronstein, Marcio C. Mancini, Margaret Boguszewski, Maria Adelaide A. Pereira, Maria Helena Senger, Maria Lúcia F. de Farias, Maria Marcílio Rabelo, Marília de Brito Gomes, Mário Vaisman, Marise Lazaretti-Castro, Mauro A. Czepielewski, Miguel N. Hissa, Milton César Foss, Mirela Jobim de Azevedo, Nelson Rassi, Osmar Monte, Paulo Tannus Jorge, Regina do Carmo Silva, Renan Montenegro, Ricardo M.R. Meirelles, Rômolo Sandrini, Rosalinda Y. Asato Camargo, Rosângela R. Réa, Rui M.B. Maciel, Ruth Clapauch, Ruy Lyra, Sandra Roberta G. Ferreira e Turíbio Leite de Barros Neto.

Nosso escritório editorial funciona hoje à perfeição, sempre limpo, agradável e organizado, graças à dedicação da Damaris e da Daniela. Sou agradecido a elas pela presteza, pelo carinho e pelos cafezinhos. Antes delas, entretanto, agradeço em nome da revista a quem dá sustentação (moral e financeira) e apoio logístico ao próprio escritório: a Diretoria Nacional da SBEM. Assim como no passado, neste ano, o atual presidente - Amélio F. de Godoy Matos - e demais diretores da SBEM-Nacional (sediada no Rio de Janeiro) não mediram esforços em prover recursos para a manutenção do escritório que, vale lembrar, é repartido com a Diretoria da SBEM-Regional de São Paulo, atualmente presidida por José Antonio M. Marcondes. Também sou grato ao Henrique e à equipe editorial da TecArt, pela contínua assistência técnica na produção e publicação da revista e à Estela e à BlueBox, pelo profissionalismo nos contatos comerciais e na captação dos sempre providenciais recursos.

Por último, mas cada vez mais importante, agradeço o interesse e a participação da indústria farmacêutica e dos laboratórios diagnósticos que, por intermédio dos responsáveis pelas equipes de decisão, estiveram envolvidos na aquisição de espaço para anúncios e propaganda na revista. A tiragem, a periodicidade, a freqüência e a qualidade da revista não seriam as mesmas não fosse a parceria comercial com as seguintes empresas, as quais agradeço (em ordem alfabética), desculpando-me de antemão pela eventual confusão no uso indevido de seus novos nomes, decorrentes de fusões e/ou incorporações mais recentes: Abbott, Asta, Aventis, Biobrás, CRIESP, Fleury, GSK, Johnson\&Johnson, Knoll, Lilly, Medley, Merck, Novartis, Novo Nordisk, Pfizer, Roche e Sanofi-Synthelabo.

Certamente faltaram os merecidos agradecimentos àqueles contribuintes cujos nomes não foram lembrados neste tempo-espaço, mas que peço, sejam condescendentes e relevem a eventual falha. Justifico-a voltando à frase inicial deste texto, quando dizia que "o tempo passa mais rápido à medida que você se torna cada vez mais maduro". Maturidade, sabedoria, consciência e razão nos transportam orgulhosamente para o paraíso do crescimento, do qual, com rapidez, somos remetidos para o inoportuno e inevitável limbo do envelhecimento que, inapelavelmente, se manifesta, entre outras pobres facetas, em incômodo esquecimento que, peremptoriamente, se traduz em ... Mas do que é mesmo que eu estava falando?

Boas festas a todos e um ótimo 2002! 